\title{
IMIGRAÇÃO E MEMÓRIA NO ROMANCE WEST OF THE JORDAN, DE LAILA HALABY
}

Maria Luiza Cardoso de Aguiar

Mestre em Letras: Literaturas de Expressão Inglesa do Programa de Pós-Graduação em Estudos Literários / UFMG

\begin{abstract}
RESUMO
O presente trabalho tem como objetivo analisar alguns aspectos da relação entre imigração e memória no romance West of the Jordan, da escritora árabe-americana Laila Halaby. Pretende-se investigar a forma como as personagens Hala e Soraya lidam com suas memórias diaspóricas e a função que tais memórias exercem para cada personagem.
\end{abstract}

\section{PALAVRAS-CHAVE}

Imigração, memória, literatura árabe-americana

A identidade de imigrantes é, a todo o momento, perpassada por questões relativas à memória, visto que o que esses indivíduos se tornam e constroem em seus novos espaços sempre se baseia, em maior ou menor grau, naquilo que eles um dia foram e viveram em seus lugares de origem. Não importa em qual extensão os imigrantes relacionam-se com suas memórias; elas sempre são essenciais no processo diaspórico que eles vivenciam. Sobre essa importância da memória, Zofia Rosińska afirma que, para o imigrante,

a memória exerce um papel triplo: ela é formadora de identidades por manter as identificações originais; é terapêutica porque ajuda a suportar as privações da transplantação a uma cultura estrangeira e é também formadora de comunidades, pois cria um vínculo entre aqueles que relembram juntos. ${ }^{1}$

No romance West of the Jordan, da escritora árabe-americana Laila Halaby, esse papel triplo da memória pode ser identificado nas personagens árabes - palestinas, em sua maioria, que vivem nos Estados Unidos. Antes que se faça uma análise mais detalhada sobre as questões de memória nesse romance, é importante que seja feita uma breve introdução sobre

\footnotetext{
${ }^{1}$ ROSIŃSKA. Emigratory experience: the melancholy of no return, p. 39.
} 
ele. West of the Jordan, escrito em 2001 e publicado em 2003, é um romance que traz as vozes de quatro narradoras-personagens intercaladas entre os diversos capítulos. Vencedor do prêmio PEN/Beyond Margins, o romance possui um tom íntimo e confessional que dá ao leitor a impressão de estar lendo uma série de passagens de diários pessoais repletos de lirismo. Apesar de possuir quatro narradoras-personagens - as primas Hala, Soraya, Khadija e Mawal -, o presente trabalho terá como foco apenas as duas protagonistas do romance, Hala e Soraya. A personagem Hala nasceu na Jordânia, tendo um pai jordaniano e uma mãe palestina; além dessa origem árabe já mista, ela também entrou em contato intenso com a cultura americana, pois durante a adolescência ela se mudou para os Estados Unidos para estudar. Soraya nasceu na Palestina, mas foi para os Estados Unidos ainda bebê.

Apesar de pertencerem à mesma família e de compartilharem muitas semelhanças, as garotas vêm de diferentes contextos e possuem especificidades muito pessoais que as fazem ter atitudes distintas em relação a suas condições de sujeitos diaspóricos. Assim, cada uma das narradoras-personagens posiciona-se diferentemente em relação a sua situação diaspórica, apesar de todas pertencerem ao mesmo grupo étnico e à mesma família. Em relação à memória, que é um componente essencial do processo de transplantação de um indivíduo a uma nova cultura, isso não é diferente. Cada narrador-personagem, no romance, cultiva relações distintas com suas memórias e é afetado por elas em diferentes proporções. Sendo assim, o presente trabalho visa analisar a forma como as personagens Hala e Soraya lidam heterogeneamente com suas memórias diaspóricas e pretende mostrar que a personagem Hala, conscientemente, lança mão de suas memórias para fazer negociações bem-sucedidas entre a cultura árabe e a americana. Enquanto isso, Soraya, indo em direção contrária a Hala, tenta evitar as memórias de sua terra natal para se integrar melhor à vida nos Estados Unidos, mas percebe que ficar isenta a essas memórias torna-se impossível.

A fim de se fazer uma análise acurada de como a personagem Hala lida com suas memórias, é essencial que o contexto diaspórico da personagem seja apresentado. O romance abre com o retorno de Hala à Jordânia, por ocasião da morte de sua avó. Esse retorno é muito significativo para a análise da "identidade dividida" de Hala, pois durante todo o romance ela tenta juntar os vários pedaços de sua identidade, incluindo aqueles que ficaram de alguma forma perdidos em sua terra natal. Nos primeiros dias que passa nesse lugar, a personagem precisa confrontar o estranhamento que sente ao reencontrar pessoas, lugares e situações que, no passado, apresentavam-se como algo mais familiar. O mesmo estranhamento existe por parte das outras pessoas em relação a ela, que parecem não reconhecê-la mais. Sobre esse desconforto trazido por sua presença, Hala afirma: 
Eu sei que eles me vêem com olhos curiosos. Eu parti antes da idade de me casar. (...) Eu deveria ter um cabelo mais comprido, eu deveria usar maquiagem. Eu não deveria usar jeans e "vestidos extremamente nãofemininos", como tia Suha diz. Eu deveria parar de usar palavras em inglês. (...) Eu estou desconectada. (...) Todos estes rostos que eu carreguei comigo por tanto tempo possuem desconfiança em seus olhos ao cumprimentaremme. Eu caminhei para muito longe deles. ${ }^{2}$

Dessa forma, Hala reconhece que não se encaixa nos padrões culturais esperados para meninas de sua idade e ela sabe que a viagem aos Estados Unidos resultou em um grande distanciamento entre ela e tudo aquilo que antes lhe parecia familiar. Stuart Hall fala sobre essa "dificuldade sentida por muitos dos que retornam em se religar a suas sociedades de origem". 3 Segundo ele, a sensação de deslocamento é comum em sujeitos diaspóricos:

Muitos sentem falta dos ritmos de vida cosmopolita com os quais tinham se aclimatado. Muitos sentem que a "terra" se tornou irreconhecível. Em contrapartida, são vistos como se os elos naturais e espontâneos que antes possuíam tivessem sido interrompidos por suas experiências diaspóricas. ${ }^{4}$

Entende-se, portanto, que seria impossível que Hala voltasse para a Jordânia sendo a mesma pessoa que era antes, visto que a experiência diaspórica deixa marcas em todos os indivíduos envolvidos e afeta não somente o modo como pensam e agem, mas também o modo como eles se relacionam com a terra natal, que também sofre reconfigurações na maneira em que é representada pelos sujeitos diaspóricos, como é o caso de Hala.

Além de todo esse estranhamento inerente aos sujeitos diaspóricos, a viagem de volta à Jordânia faz também com que Hala entre em contato com memórias desagradáveis do tempo em que ela vivia naquele lugar. Essas memórias são relacionadas, principalmente, ao embate que a personagem tinha com aspectos da cultura árabe que não pareciam ser apropriados para ela. A menina se lembra, por exemplo, de quando ela era zombada por gostar de ler. Ela afirma:

$\mathrm{Eu}$ passava muito tempo sozinha, lendo, e isso era uma fonte de constrangimento e preocupação para quase todos da minha família. "Ela estará cega antes de completar quinze anos," tia Suha, irmã de meu pai, me dizia todas as vezes em que ela vinha e me encontrava inclinada sobre um

\footnotetext{
2 "I know they see me with curious eyes. I left before marrying age. (...) I should have longer hair, I should wear makeup. I should not wear blue jeans and 'extremely unfeminine dresses,' as Aunt Suha says. I should stop using English words (...). I am unconnected. (...) all those faces I've carried with me for so long wear suspicion in their eyes as they greet me. I have walked so far away from them" (HALABY. West of the Jordan, p. 77, tradução nossa).

${ }^{3}$ HALL. Da diáspora: identidades e mediações culturais, p. 27.

${ }^{4}$ HALL Da diáspora: identidades e mediações culturais, p. 27.
} 
livro. "Vocês não deviam deixá-la fazer isso ou ninguém irá querer se casar com ela."

Outra forte lembrança que ocupa grande parte dos pensamentos de Hala durante essa estadia na Jordânia diz respeito à outra volta que ela havia feito a sua terra natal, depois de já estar morando nos Estados Unidos, quando a mãe faleceu. Naquela ocasião, Hala havia confrontado seu pai veementemente, pois ele queria que a filha permanecesse na Jordânia definitivamente para "colocar suas raízes lá como uma mulher". 6 Consciente de que fixar raízes como uma mulher, naquela cultura, significaria interromper os estudos, casar-se com um marido desconhecido e ter filhos, Hala se nega a obedecer à decisão de seu pai e retorna aos Estados Unidos.

Apesar de a relação de Hala com o pai, no momento em que ela retoma essas lembranças, ter melhorado consideravelmente, e apesar de a personagem já ter superado a perda da mãe, tais lembranças ainda se apresentam à personagem como algo extremamente doloroso. Sobre isso, Hala afirma: "Eu não consigo apagar a imagem da minha última visita, o funeral de minha mãe, e depois a enorme briga. A memória vem em meus olhos, queimando como o sol que está se pondo..."7 $\mathrm{O}$ encontro de Hala com essas lembranças ruins faz com que o tempo, durante os primeiros dias de sua estadia na Jordânia, seja, como a própria personagem descreve, um "borrão de memórias e pesadelos". ${ }^{8}$ Entretanto, aos poucos, os dias de Hala em sua terra natal tornam-se mais agradáveis, pois ela consegue ver o que há além das memórias ruins e dos pesadelos e passa a entrar em contato com lugares e pessoas que marcaram sua infância de forma extremamente positiva. Assim, o contato que Hala tem, na Jordânia, tanto com as memórias boas quanto com as ruins, influencia fortemente na construção de sua identidade, que passa a ser formatada por tudo aquilo que ela um dia viveu.

Essa influência que as memórias exercem sobre a formação de identidades remete ao primeiro papel da memória citado por Rosińska, na introdução do presente trabalho. Como explicitado anteriormente, de acordo com Rosińska, a memória ajuda os imigrantes a

\footnotetext{
5 "I spent a lot of time alone reading, a source of embarrassment and concern for almost everyone in my family. 'She will be blind before she is fifteen years old,' Aunt Suha, my father's sister, would tell me every time she came over and found me bent over a book. 'You shouldn't let her do this or no one will marry her"' (HALABY. West of the Jordan, p. 8, tradução nossa).

${ }^{6}$ A partir desse ponto, todas as traduções presentes no trabalho são nossas. "and put your roots here as a woman" (HALABY. West of the Jordan, p. 45).

7 "I can't erase the picture of my last visit, my mother's funeral, and then the huge fight. The memory comes in my eyes, burning like the sun that's setting..." (HALABY. West of the Jordan, p. 13).

8 "a blur of memories and nightmares" (HALABY. West of the Jordan, p. 77).
} 
formarem suas identidades, por manterem as "identificações originais". 9 Assim, quando Hala entra em contato com as memórias da cultura árabe e de sua terra natal, ela se aproxima dessas identificações originais, mesmo que elas, muitas vezes, não sejam exatamente agradáveis. Além disso, as memórias funcionam como mediadoras para essa personagem que vive no encontro de duas culturas virtualmente distintas, e que, ao longo do romance, sofre os conflitos oriundos da sua condição diaspórica e híbrida. Segundo o teórico Stuart Hall, a transplantação de indivíduos a uma nova cultura, "trata-se de um processo de tradução cultural, agonístico uma vez que nunca se completa, mas que permanece em sua indecidibilidade". ${ }^{10}$ Portanto, como uma forma de "resolver" esses conflitos descritos por Hall, na medida em que isso é possível, Hala recorre justamente às memórias de sua terra natal para iniciar um processo de construção de identidade que valoriza a cultura árabe, sem, entretanto, desvalorizar a cultura americana.

Assim, ao final do romance, quando Hala volta à sua casa nos Estados Unidos, uma passagem extremamente significativa mostra que a personagem encontra uma forma de não deixar que suas memórias morram: ela recorre a objetos que remetem ao seu passado e à cultura árabe e os leva para o seu quarto, onde eles passam a figurar, em meio a tantos símbolos da cultura americana, como vestígios de um passado que foi e é determinante para a construção de sua identidade. Ao final do romance, Hala afirma:

Eu mergulho de ponta-cabeça dentro dessa caixa de fotos e fico lá dentro até que elas cubram o interior de meus olhos. Em breve a aparência de nossas paredes não terá mais importância, porque todas as vezes que eu olhar para cima, eu verei Ma [a mãe] sorrindo para mim, ou Sitti [a avó] descascando cenouras, ou Latifa [a irmã] derramando chá em um marido em potencial. Lembre-se por você e pelo seu amanhã. (...) Lembre-se das histórias de Nawara [cidade de sua mãe, na Palestina]: tudo, incluindo as tragédias ${ }^{11}$.

Essa caixa de fotos pode ser considerada como o que Pierre Nora chama de "lugares de memória”. Segundo Nora, esses lugares servem para que se evoque o passado, visto que "não há memória espontânea""12 e são sempre revestidos por uma "aura simbólica". Sobre essa aura, Nora afirma: "Mesmo um lugar puramente funcional, como um manual de aula, um

\footnotetext{
${ }^{9}$ ROSIŃSKA. Emigratory experience: the melancholy of no return, p. 39.

${ }^{10}$ HALL. Da diáspora: identidades e mediações culturais, p. 74.

11 "I dive headfirst into this box of photos and stay inside until they paper the insides of my eyes. Soon it won't matter what our walls are like because every time I look up I will see Ma smiling at me, or Sitti peeling carrots, or Latifa spilling the tea on a prospective husband. Remember for yourself and for your tomorrow (...) Remember the stories of Nawara: everything, including the tragedies" (HALABY. West of the Jordan, p. 219).

${ }^{12}$ NORA. Entre história e memória: a problemática dos lugares, p. 13.
} 
testamento, uma associação de antigos combatentes, só entra na categoria se for objeto de um ritual." ${ }^{\prime 13}$ Assim, a caixa de fotos de Hala e posteriormente as paredes de seu quarto, tornam-se lugares de memória, pois a personagem deposita nesses objetos a forte intenção de que sua vida pregressa não seja esquecida. Portanto, através dessas atitudes, Hala demonstra perceber, agora, que suas memórias, inclusive as tragédias, integram sua identidade e funcionam como um elo entre o que ela é no presente e o que um dia foi, visto que o passado na Jordânia e a cultura árabe exercem enorme influência na constituição de sua subjetividade hoje.

Além disso, quando a cultura americana parece, para ela, extremamente alheia e distante, suas memórias são o que a fazem sentir-se vinculada a algo maior e mais significativo, constituindo o que Rosinska classifica como a função terapêutica da memória. Quando as paredes de sua casa americana pareceram-lhe extremamente brancas e sem vida, suas lembranças foram o que a fizeram preencher, literalmente, todos aqueles espaços vazios. Se no início da história, Hala sentia-se como um "amuleto sem uma corrente na qual segurarse", ${ }^{14}$ é exatamente quando ela entra em contato com suas memórias que ela passa a ser parte de algo, e é dessa forma que a memória passa a ter uma função terapêutica para a personagem.

Após espalhar as fotos pelo quarto, Hala reflete sobre o novo significado trazido por essas imagens:

Ao entardecer as paredes vazias são toleráveis, vívidas, diferentes e familiares. Eu me sento no chão e as encaro, depois fecho meus olhos. Já é noite em Amã - e em Nawara - e eu guardei minhas memórias debaixo do cobertor áspero, desejando a elas os sonhos mais doces enquanto abro meus olhos para um mundo novo, mas não desconhecido. ${ }^{15}$

Sendo assim, o que antes era quase insuportável para Hala, torna-se bastante tolerável e repleto de novos significados, uma vez que o contato da personagem com suas memórias permite que ela se sinta mais confortável e familiarizada com o que antes estava relacionado apenas a deslocamento e desconforto. É interessante perceber, também, que Hala conhece a hora apropriada de descentralizar essas memórias e tirá-las de seu foco principal, ao dizer que ela as guardou debaixo do cobertor. Hala reconhece o importante papel que as memórias

\footnotetext{
${ }^{13}$ NORA. Entre história e memória: a problemática dos lugares, p. 21.

14 "and so I remain unconnected, like a charm without a chain to hang from" (HALABY. West of the Jordan, p. 83).

15 "By the evening the bare walls are bearable, lively, different and familiar. I sit on the floor and stare, then close my eyes. It is deep nighttime in Amman - and in Nawara - and I have tucked my memories under a scratchy blanket, wishing them the sweetest dreams as I open my eyes to a new, but not unfamiliar world" (HALABY. West of the Jordan, p. 220).
} 
exercem, mas sabe que há um mundo novo que, apesar de ter sido descoberto com a ajuda dessas lembranças, vai muito além delas.

Diferentemente de Hala, a personagem Soraya parece evitar as memórias relacionadas à cultura árabe, apesar de não ser bem-sucedida nessas tentativas, como será mostrado posteriormente. Soraya é filha de pais palestinos, nasceu na Palestina, mas se mudou para os Estados Unidos ainda criança. Entre as quatro personagens principais do romance, Soraya se apresenta como a mais americanizada e, à primeira vista, o leitor tem a impressão de que ela está completamente integrada à cultura americana. Soraya transgride as tradições árabes por não concordar com elas e apresenta comportamentos muito diferentes daqueles esperados por sua família e pela comunidade árabe, em geral: em casamentos e festas árabes, as danças de Soraya são consideradas muito provocativas e exageradas; ela mente a seus pais para poder sair de casa e encontrar-se com homens - um comportamento inaceitável para jovens árabes; ela usa roupas que muitas vezes não são consideradas apropriadas para uma menina árabe. Além de todas essas atitudes transgressoras, Soraya ainda se orgulha imensamente de ser diferente de sua mãe e das outras mulheres da família, considerando-se parte de "uma nova espécie, uma jovem rebelde". ${ }^{16}$

Uma possível razão para esse distanciamento entre Soraya e a cultura árabe diz respeito à ausência de memórias de sua terra natal. Como a personagem se mudou para os Estados Unidos muito jovem, ela não cultiva muitas lembranças da Palestina e de sua família que ficou para trás. A ausência dessas memórias faz com que faltem à Soraya referências mais sólidas de sua cultura e de sua comunidade, o que a leva a sentir, ao longo do romance, um maior pertencimento à cultura americana do que à cultura árabe. Um contraponto à situação de Soraya é justamente a personagem Hala, examinada anteriormente neste trabalho, pois Hala, tendo se mudado para os Estados Unidos já no final da adolescência, possui muitas memórias que funcionam como referenciais para que ela continue próxima da cultura árabe.

Segundo Andreas Huyssen, as gerações posteriores de imigrantes, como é o caso de Soraya, têm preocupações diferentes daquelas das primeiras gerações, como é o caso de Hala, e não enxergam as memórias vinculadas a seus lugares de origem da mesma forma que seus pais e avós, por exemplo. Huyssen afirma que

a compreensão tradicional de diáspora como perda da terra natal e desejo de retorno torna-se irrelevante para as segundas e terceiras gerações (...) que não são mais familiarizadas com a língua e a cultura do país de seus ancestrais. Não importa se eles descrevem-se como sujeitos diaspóricos; os

\footnotetext{
16 "I am a new breed. A rebel" (HALABY. West of the Jordan, p. 56).
} 
problemas-chave concentram-se mais na relação deles com a cultura nacional na qual eles vivem do que no imaginário das raízes na cultura dos ancestrais. Seus problemas são primariamente um problema de vida no presente e negociação com a cultura anfitriãa, ${ }^{, 17}(2003$, p. 162)

Dessa forma, para Soraya, diferentemente do que ocorre com as primeiras gerações, o estabelecimento de conexões firmes com os Estados Unidos torna-se muito mais importante do que o cultivo das memórias da comunidade árabe, visto que são essas conexões com o país anfitrião que definem como será a vida da personagem e como ela será vista pelas pessoas daquela nova comunidade. Portanto, para Soraya, a preocupação e os investimentos que ela faz devem residir no presente, e para ela, esse tempo está estritamente relacionado aos Estados Unidos.

O comportamento de Soraya diante das memórias e da cultura árabe é fonte de conflitos entre ela e sua mãe, que acredita que a filha foi seduzida pela ilusão americana, deixando suas raízes de lado. Sobre isso, Soraya faz a seguinte afirmação: "Minha mãe é frustrada, pois eu não sou uma boa filha, mas ela se recusa a admitir que ela tenha alguma coisa a ver com isso e diz, em vez disso, que eu tenho uma personalidade fraca e que 'fui enganada pela mentira que é a América""18 Ao dizer que Soraya não é uma "boa filha", a mãe da personagem deixa implícito que uma boa filha é aquela que segue estritamente o que espera a cultura árabe. Entretanto, é impossível que Soraya tenha tal conduta ou cultive memórias de sua terra natal, se ela viveu a maior parte de sua vida nos Estados Unidos. É interessante perceber também, através dessa citação, que Soraya culpa a mãe por tê-la levado para um país distante e muito diferente da Palestina, e ainda assim esperar que ela tenha uma conduta condizente com os valores árabes e tenha fortes vínculos com a vida que levava antes.

Assim, Soraya definitivamente não consegue compreender como os árabes que se mudam para os Estados Unidos podem querer continuar a viver da mesma forma que viviam antes, mesmo após estarem em um outro país. Ela diz: “Todas as pessoas mais velhas agem da

\footnotetext{
17 "The traditional understanding of diaspora as loss of homeland and desire to return itself becomes largely irrelevant for the second and third generations who (...) are no longer conversant in language and culture of the country of their ancestors. Whether or not they were to describe themselves as diasporic subjects, the key problems lie in their relation to the national culture they live in rather than to the imaginary of roots in the culture of ancestors. It is primarily a problem of life in the present and the negotiation with the host culture" (HUYSSEN. West of the Jordan, p. 162).

18 "My mother is disappointed because I am not a good daughter, but she won't admit she has anything to do with it and says instead that I have a weak spirit and have been 'taken in by the lie that is America"" (HALABY. West of the Jordan, p. 24-25).
} 
mesma forma que agiam quando estavam em casa, o que é injusto de várias formas, porque nós estamos na América, mas eles nos dizem que não deveríamos estar levando uma vida americana."19 Além disso, em outro momento do romance, ao refletir sobre o que seu tio, Haydar, disse a ela em relação à perda de um país e de um lar, o posicionamento da menina em relação às lembranças do que ficou para trás torna-se ainda mais claro:

Perder um país é o que faz seus olhos dançarem, é o que meu tio Haydar me contou certa vez. Isso funciona para ele, porque ele perdeu seu país. Apesar de nós termos vindo do mesmo lugar e de eu ter vindo do avô que era o pai dele, eu estou aqui [nos Estados Unidos] há tempo demais, com um pai que quer ser muito bem-sucedido para perder meu país. Meus olhos dançam porque eu estou viva, mas eu não digo isso a Haydar. ${ }^{20}$

Portanto, diferentemente das gerações de imigrantes anteriores, Soraya não sente que perdeu um país, pois, na situação em que vive atualmente - quando seus olhos estão voltados para o presente e não para o passado -, ela nem mesmo considera que um dia teve alguma relação de pertencimento com outro lugar que não fosse os Estados Unidos. Assim, os olhos de Soraya não dançam por ela ter perdido um país, uma vez que, segundo ela, não se pode perder o que nunca se teve de fato.

O que Soraya não tem também, como foi brevemente discutido anteriormente, são as memórias relacionadas à Palestina e à cultura árabe. As teóricas da diáspora, Anita Mannur e Jana Evans Braziel, apontam para o problema das segundas e terceiras gerações de imigrantes através de alguns questionamentos:

O que acontece quando alguém não consegue ou não quer olhar para trás (...)? O que acontece quando as futuras gerações não sabem como olhar para trás, ou como Karin-Aguilar San Juan aponta, se olhar para trás significa olhar para trás em um lugar dentro dos Estados Unidos, onde eles passaram sua infância, e não olhar para algum início primordial no país de origem?"21

19 "The older people all act the same way they did when they were home, which isn't fair in a lot of ways because we're in America now, but they tell us we are not supposed to be living an American life" (HALABY. West of the Jordan, p. 31).

20 "Losing a country is what makes your eyes dance, is what my Uncle Haydar told me once. That works for him because he has lost his country. Even though we come from the same place, and I am from the grandfather who was his father, I have been here too long with a father who wants to be too successful for my country to be lost. My eyes dance because I am alive, but I don't tell Haydar that..." (HALABY. West of the Jordan, p. 115).

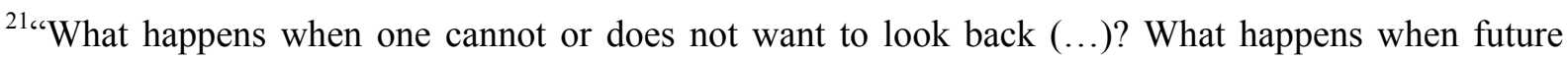
generations do not know how to look back, or as Karin-Aguilar San Juan notes, if looking back means looking back to a place within the United States where they spent their childhood and not to some primordial beginning in the home country?" (BRAZIEL; MANNUR. Theorizing diaspora: a reader, p. 9). 
Tais perguntas, que são fundamentais para a compreensão das gerações mais jovens das comunidades em diáspora, mostram que essas gerações cultivam relações diferentes daquelas de seus pais e avós, tanto com o país de origem quanto com o país anfitrião. $\mathrm{O}$ aspecto ambivalente das memórias desses indivíduos, apontado por Braziel e Mannur, é extremamente relevante, pois alguns desses indivíduos, como a personagem Soraya, não possuem memórias individuais de seus países de origem, uma vez que eles saíram de lá muito jovens. Todas as memórias às quais eles têm acesso são construídas pelas gerações que vieram antes deles, e, assim, o contato que Soraya, por exemplo, tem com a cultura árabe é sempre mediado por seus pais e parentes, os quais de fato possuem essas memórias.

Conseqüentemente, o modo pelo qual Soraya se relaciona com essa cultura e a importância que ela tem na vida da personagem obviamente diferem-se daquelas pessoas que têm, ou tiveram um contato mais intenso com ela. No romance, Hala, consciente da maneira como as gerações posteriores lidam com as memórias, sintetiza adequadamente a situação dessas pessoas. Ao refletir sobre essa situação, ela pensa: "Lembre-se dos mais jovens, que vieram para cá ainda bebês, mas não podem se lembrar daquilo que eles não viram e, assim, não possuem nenhuma razão para comportarem-se adequadamente. ${ }^{, 22}$ Em outras palavras, Hala entende que esperar que as gerações posteriores de imigrantes comportem-se de acordo com os valores e as tradições árabes é irrealista, uma vez que, muitas vezes, essas pessoas simplesmente não possuem as lembranças dessas tradições e valores.

Entretanto, se por um lado Soraya não consegue ter essas memórias individuais, por outro, através das memórias coletivas da comunidade árabe, ela cria certa conexão com seu país de origem. Ao longo do romance, Soraya narra quatro histórias que são inteiramente relacionadas ao mundo e ao povo árabe. Através dessas histórias, a menina que, à primeira vista, é extremamente americanizada, aproxima-se consideravelmente de sua comunidade, tanto através do conteúdo das histórias, quanto através dos momentos em que ela as narra em festas e reuniões familiares. Esse aspecto coletivo da memória está relacionado a uma das funções da memória para imigrantes, segundo Rosińska, mostradas neste trabalho. Essa função, ligada à formação de comunidades de pessoas que relembram juntas, está vinculada à criação de uma memória coletiva. Sobre isso, Michael Pollak, em seu texto "Memória e identidade social", mostra que inicialmente a memória pode ser entendida como algo individual, mas ele destaca o fato de que Maurice Halbwachs, nos anos 1920 e 1930 “já havia

\footnotetext{
22 "Remember the young ones, who came here as babies, but who cannot remember what they have not seen and therefore have no reason to behave" (HALABY. West of the Jordan, p. 219).
} 
sublinhado que a memória deve ser entendida também, ou sobretudo, como um fenômeno coletivo e social, ou seja, como um fenômeno construído coletivamente e submetido a flutuações, transformações, mudanças". ${ }^{23}$ Esse aspecto cambiante da estrutura da memória dita tradicional e seu entendimento como um fenômeno continuamente construído nos remetem, imediatamente, à condição diaspórica, que também se configura como uma condição fragmentada, coletiva, flutuante e em permanente transformação, e também à própria memória diaspórica.

Huyssen, no texto "Diaspora and nation: migration into other pasts", faz exatamente essa aproximação entre a memória no seu sentido tradicional e memória diaspórica. Ele afirma que a primeira,

é por definição separada, híbrida, deslocada, dividida. Esse fato fundamenta a afinidade entre a memória diaspórica e a estrutura da própria memória, que é sempre baseada no deslocamento temporal entre o ato da lembrança e o conteúdo daquilo que é lembrado, um ato que é mais de recherche do que de recuperação. $^{24}$

Assim, a memória diaspórica de que Huyssen fala não está esperando, intacta e preservada, por um resgate, uma vez que é impossível recuperá-la exatamente tal como ela costumava ser no passado; ela sofre transformações múltiplas e por isso deve ser compreendida como um fenômeno que é pesquisado, investigado, construído, representado e sempre deslocado.

A propósito, o fato de Soraya parecer rejeitar, muitas vezes, a memória da comunidade árabe não significa que ela não seja afetada por essas memórias. Ela, apesar de ser adolescente, carrega consigo vestígios das memórias que ocorreram fora de seu tempo-espaço, como o início da ocupação da Palestina pelos israelenses e também a transplantação de sua comunidade a um novo país - tópicos presentes em todas as quatro histórias que ela narra ao longo do romance. De acordo com Pollak, esses acontecimentos vividos "por tabela" constituem justamente a memória coletiva e

são acontecimentos dos quais a pessoa nem sempre participou, mas que, no imaginário, tomaram tamanho relevo que, no fim das contas, é quase impossível que ela consiga saber se participou ou não. Se formos mais longe,

\footnotetext{
${ }^{23}$ POLLAK. Memória e identidade social, p. 201.

24 "Diasporic memory in its traditional sense is by definition cut off, hybrid, displaced, split. This fact grounds the affinity of diasporic memory to the structure of memory itself which is always based on temporal displacement between the act of remembrance and the content of that which is remembered, an act of recherche rather than recuperation" (HUYSSEN. Migration into other pasts, p. 152).
} 
a esses acontecimentos vividos por tabela vêm se juntar todos os eventos que não se situam dentro do espaço-tempo de uma pessoa ou de um grupo. ${ }^{25}$

Portanto, essa "memória herdada" da qual Pollak trata é aquela que inevitavelmente faz parte da identidade de Soraya, mesmo ela tendo tão poucas memórias individuais. A memória da comunidade árabe é também a memória de Soraya e esse vínculo manifesta-se nas muitas histórias narradas pela personagem.

Sobre a relação entre memória e identidade, Pollak afirma ainda que "a memória é um elemento constituinte do sentimento de identidade, tanto individual como coletiva, na medida em que ela é também um fator extremamente importante do sentimento de continuidade e de coerência de uma pessoa ou de um grupo em sua reconstrução de si". ${ }^{26}$ Pode-se afirmar, assim, que Soraya, ao narrar histórias de sua comunidade e ao entrar em contato com a memória coletiva da mesma, está reconstruindo sua identidade e criando vínculos que até então pareciam não existir. Assim, ao final do romance, a personagem chega ao ponto de retomar lembranças da Palestina, desejando, por um momento, retornar a esse lugar: "Quem iria pensar que eu iria querer voltar, apenas para observar minha avó contemplando o dia que repousa vagaroso e gordo como uma melancia, observar o céu nos observando, implorar para o sol nos cobrir calmamente.",27

Assim, o presente trabalho mostrou como, no romance West of the Jordan, a memória opera para as personagens Hala e Soraya. Para a primeira, que é parte da primeira geração de imigrantes, a memória é conscientemente utilizada para a criação de negociações bemsucedidas entre a cultura árabe e a americana. Para Soraya, parte da segunda geração de imigrantes, a relação com a memória mostra-se mais complexa, uma vez que é esperado que a personagem haja em conformidade com memórias que ela sequer possui. Entretanto, ao narrar histórias relacionadas à Palestina e a imigrantes árabes nos Estados Unidos, Soraya entra em contato com a memória coletiva da comunidade e isso faz com que os vínculos entre ela e a cultura e a comunidade árabes não sejam de todo inexistentes. Dessa forma, apesar de operar diferentemente para Hala e Soraya, a memória funciona, para as duas personagens, como elemento essencial para a constituição de suas identidades diaspóricas e para o estabelecimento de conexões - em diferentes graus - com a cultura e comunidade árabes.

\footnotetext{
${ }^{25}$ POLLAK. Memória e identidade social, p. 201.

${ }^{26}$ POLLAK. Memória e identidade social, p. 204.

27 "Who would think I would want to go back, just to watch my grandmother watching the day that sits slow and fat like a watermelon, to watch the sky watching us, to beg for the sun to cover us quietly" (HALABY. West of the Jordan, p. 191).
} 


\begin{abstract}
The present article has, as its main objective, the analysis of the relation between immigration and memory in West of the Jordan, by Laila Halaby. It aims at investigating the way through which the characters Hala and Soraya deal with their diasporic memories as well as the role played by these memories.
\end{abstract}

\title{
KEYWORDS
}

Immigration, memory, Arab-American literature

\section{REFERÊNCIAS}

BRAZIEL, Jana Evans; MANNUR, Anita (Ed.). Theorizing diaspora: a reader. Malden: Blackwell Publishing, 2005.

HALABY, Laila. West of the Jordan. Boston: Beacon Press, 2003.

HALL, Stuart. Da diáspora: identidades e mediações culturais. Organização de Liv Sovik. Trad. Adelaine La Guardia Resende et. al. Belo Horizonte: Ed. UFMG, 2003.

HUYSSEN, Andreas. Migration into other pasts. New German Critique, v. 88, p. 147-164, 2003.

NORA, Pierre. Entre história e memória: a problemática dos lugares. Trad. Yara Aun Khury. Revista Projeto História, São Paulo, v. 10, p. 7-28, 1993.

POLLAK, Michael. Memória e identidade social. Estudos Históricos, Rio de Janeiro, v. 5, n. 10, p. 200-212, 1992.

ROSIŃSKA, Zofia. Emigratory experience: the melancholy of no return. In: CREET, Julia; KITSMANN, Andreas (Ed.). Memory and migration: multidisciplinary approaches to Memory Studies. Toronto: University of Toronto Press, 2011. p. 29-41. 